\title{
Germanica
}

$11 \mid 1992$

Le Conte dans les littératures germaniques du XXe siècle

\section{Und da sie nicht gestorben sind, so leben sie heute noch...}

\section{Erika Tunner}

\section{(2) OpenEdition}

\section{Journals}

Édition électronique

URL : http://journals.openedition.org/germanica/1336

DOI : 10.4000/germanica.1336

ISSN : 2107-0784

Éditeur

Université de Lille

Édition imprimée

Date de publication : 1 janvier 1992

Pagination : 13-17

ISSN : 0984-2632

\section{Référence électronique}

Erika Tunner, « Und da sie nicht gestorben sind, so leben sie heute noch... », Germanica [Online], 11 |

1992, Online erschienen am: 07 Februar 2014, abgerufen am 06 Oktober 2020. URL : http://

journals.openedition.org/germanica/1336 ; DOI : https://doi.org/10.4000/germanica.1336

Ce document a été généré automatiquement le 6 octobre 2020.

(c) Tous droits réservés 


\title{
Und da sie nicht gestorben sind, so leben sie heute noch...
}

\author{
Erika Tunner
}

Wo sind heute die Mütter und Großmütter, die ihren Kindern vor dem Schlafengehen noch Märchen erzählen? Das Fernsehen sorgt am Abend für unterhaltsamere Geschichten. Und doch sind Märchen «in» und werden nie «out» sein: ganze Märchen oder einzelne Märchenmotive sind ständig im Umlauf. Dafür sorgen einerseits die zahlreichen Märchenausgaben, die immer wieder aufgelegt werden, angefangen von der Standardsammlung der Brüder Grimm, über Ludwig Bechstein, Hans Christian Andersen, bis zu den «schönsten Märchen» aus Afrika, Amerika, China, Indien, Japan, Vietnam... Andererseits haben sich auch eine Reihe von Schriftstellern der Gegenwart verschiedener Märchenstoffe bedient und sie auf ihre Weise variiert, modernisiert, parodiert, um- und weitergedichtet. Dabei werden psychologische oder gesellschaftspolitische Probleme aufgedeckt, Märchenweisheiten infrage gestellt, zeittypische Charaktere eingeführt, neue Handlungs- und Erzählformen ausprobiert. Oft sind diese Märchen in Sammelbänden erhältlich, wie etwa Grimms Märchen - modern (1979), Neues vom Rumpelstilzchen (1981), Daumesdick (1990), um nur einige zu nennen. Die beliebtesten Märchen, die offenbar am meisten zu humorvoller oder kritischer Auseinandersetzung herausfordern, sind Hansel und Gretel, Schneewittchen, Dornröschen, Rotkäppchen, Die Sterntaler, Der Froschkönig, Der Wolf und die sieben jungen Geißlein.

Was man dabei und daraus machen kann, mag kurz ein Blick auf die SchneewittchenBearbeitungen zeigen. Am Anfang des Jahrhunderts... war Robert Walser. In seinem Dramolett Schneewittchen (1901), das 1987 ins Französische übersetzt wurde ${ }^{2}$, wird das bekannte Märchengeschehen als Vorgeschichte vorausgesetzt; das Spiel beginnt, nachdem der Prinz als Retter aufgetreten ist und bevor die Königin sich tottanzen muß. Das Hauptthema ist die Auseinandersetzung zwischen Mutter und Tochter, ein Spannungsfeld, das seit den siebziger Jahren zu den Lieblingsthemen gesellschaftskritischer Autoren, vor allem Autorinnen gehört, die von der Überzeugung 
ausgehen, daß nicht nur das Verhältnis zwischen Vater und Sohn, sondern auch dasjenige zwischen Mutter und Tochter ambivalent und konfliktanfällig ist ${ }^{3}$. Willy Pribil parodiert 1961 die psychoanalytische Deutung in seinem Text Schneewittchen - frei nach Sigmund Freud: die Königstochter liebt ihren Vater, denn sie hat einen verdrängten Elektrakomplex, die Stiefmutter, von Sexualneid befallen, befiehlt mit einer stark sadistischen Triebkomponente den Tod des Mädchens, das jedoch dem letalen Ausgang entgeht. Nachdem es sich der Reihe nach in die Betten der sieben Zwerge gelegt hat, was keines weiteren Kommentars bedarf, stirbt es an einer Apfelvergiftung. Von den exhibitionistischen Zwergen wird es in einem gläsernen Sarg zur Schau gestellt und von einem nekrophilen Prinzen, der es für eine Leiche hält, wachgeküßt. Der Leser sieht unschwer eine Ehe voraus, die sich für einen Psychiater als sehr lukrativ erweisen wird $^{4}$.

3 Mit Was ist aus Schneewittchens Stiefmutter geworden? (1970) erzählt Reiner Kunze ein politisches Märchen, wo man sich im Lande der tyrannischen Königin bespitzelt und überwacht, und schließlich scharenweise in ein anderes Königreich ziehen will. Doch auch tyrannische Königinnen müssen sterben, insbesondere, wenn kecke junge Schneidergesellen namens Hans auftreten und behaupten, ihre Marie, ein Mädchen aus dem Volke, sei doch die Schönste im ganzen Land. Da müssen die Minister fliehen und Hans und Marie werden zu den neuen Herrschern ernannt und das Volk ist nun selbstverständlich auch gleich eines der glücklichsten. «Im Märchen jedenfalls müßte es so sein. Oder so ähnlich», endet Reiner Kunze, «was aber ist wirklich aus dem Schneidergesellen geworden, als er gesagt hatte, Marie sei schöner als die Königin?» ${ }^{5}$

Michael Kumpe evoziert in humorvoller Weise ein emanzipiertes Schneewittchen in seinem gleichnamigen Gedicht aus dem Jahre 1975. Das Mächen scheuert und kocht und wäscht für sieben Tröpfe, bis es eines schönen Tages in den Streik tritt, meinend, daß die Zwerge solche Sachen ja schließlich auch selber machen könnten. Kommt ein Prinz und holt sie auf sein Schloß, nicht nur weil Schneewittchen so schön ist, sondern weil sie sich auch so gut in der Hausführung auskennt. Zu ihrer Belustigung darf sie in den Mußestunden mit Puppen spielen. Wen wundert es, daß Schneewittchen von Zwergen und Prinzen bald genug hat und sich auf- und davonmacht? 6

Dann ist da noch das 1964 entstandene, ganz zeitlose Professoren-Liedchen von Martin Walser, das seiner Kürze halber zur Gänze hier wiedergegeben werden soll:

Büchlein Büchlein an der Wand

wer ist der Klügste im ganzen Land?

Der Doktor Doli, der Daktor Dall

der Diktor Dill, der Duktor Dull

das ist der Klügste im Land.

Büchlein, Büchlein,

das sollst Du mir büßen?

6 Aber es gibt auch ganz neue Märchen, zu denen unter anderen die von Franz Fühmann gehören. In der Sammlung Daumesdick findet sich ein Märchen, das mit der Umwelt von heute arbeitet: Der Aufzug von Paul Maar. Ein Mädchen wohnt mit ihren Eltern in einem modernen Hochhaus, die Eltern gehen abends beide aus - in die Volkshochschule. Das Mädchen, Dornröschen in Betonwände eingeschlossen, kann nicht schlafen: der Fahrstuhl rauscht hinauf und hinunter. Was soll man da machen, in Hochhäusern geht man eben nicht mehr über Wendeltreppen. So lauscht das Mädchen auf die Geräusche des Fahrstuhls, und siehe da, aus den Geräuschen werden die schönsten Phantasien über ihre Lebenswelt ${ }^{8}$. 
7 Eine originelle Idee von Gisela Craichen und Hans Helmut Hinrichs war es, bekannte Künstler, Schriftsteller, Politiker und Wissenschaftler aufzufordern, einen Brief an jene Märchenfigur zu richten, die sie am meisten beeindruckt hat. Geschrieben wurde an den kleinen Prinzen genauso wie an das Rotkäppchen, an das Aschenputtel, an Hans im Glück, und an Schneewittchen ${ }^{9}$. Schreib mal wieder...

Auch die Märchenforschung geht neue Wege, vom Märchen-helden zum Manager, zum Beispiel. Mit Beiträgen zum «Ökonomieverständnis der Literatur» befaßten sich jüngst eine Reihe von Literarhistorikern, welche die wirtschaftlichen Ideale und Modelle untersuchten, die in den Märchen aufscheinen. Welchen Berufsgruppen begegnen wir und was sagen diese über das Leben der Märchenfiguren aus? ${ }^{10}$ Wie weit sind sie auf das Lesepublikum hin stilisiert worden?

9 Lüg mir nicht's vor, «erzähl mir keine Märchen».

10 Kaum eine andere literarische Gattung eignet sich so gut dafür, im Blätterwald der Bücher die Wahrheit zu sagen.

\section{NOTES}

1. $\mathrm{Zu}$ den neueren Märchensammlungen von Autoren des 20. Jahrunderts, vgl. u.a.: Grimms Märchen - modern. Prosa, Gedichte, Karikaturen, hg. von Wolfgang Mieder, Stuttgart, Reclam 1979. Neues vom Rumpelstilzchen, hg. von Hans-Joachim Gelberg, Weinheim/Basel, Beltz \& Gelberg, 1981. Daumesdick, Der neue Märchenschatz, hg. von Hans-Joachim Gelberg, Weinheim/Basel, Beltz \& Gelberg, 1990.

2. - Blanche-Neige, traduction de Claude Mouchard, Paris, Le Nouveau Commerce, 1987. Zu Robert Walser, vgl. auch Robert Walsers literarische Gratwanderungen, hg. von Erika Tunner, Germanica, numéro hors-série, 1/1991.

3. - Zum Themenkreis vgl. Heidy Margrit Müller, Töchter und Mütter in deutschsprachiger Erzählprosa von 1885-1935, München, iudicium, 1991.

4. - Willy Pribil, Schneewittchen - frei nach Sigmund Freud, in : Grimms Märchen - modern, S. 44-45.

5. - Reiner Kunze, Was ist aus Schneewittchens Stiefmutter geworden? Ebd., S. 45-51.

6. - Michael Kumpe, Schneewittchen. Ebd., S. 53-54.

7. - Martin Walser, Professoren-Liedchen, Ebd., S. 45.

8. - Daumesdick. Der neue Märchenschatz, hg. von Hans-Joachim Gelberg.

9. - Und weil sie nicht gestorben sind... Briefe an Märchenfiguren, hg. von Gisela Craichen / Hans Helmut Hillrichs, München, Hoffmann und Campe, 1991.

10. - Der literarische Homo oeconomicus. Vom Märchenhelden zum Manager. Beiträge zum Ökonomieverständnis in der Literatur, hg. von Werner Wunderlich, Reihe «Facetten deutscher Literatur», St. Galler Studien, Bern/Stuttgart, Paul Haput Vlg., 1989. 


\section{RÉSUMÉS}

Märchen sind nie Mode, sondern immer wieder modern. Märchenhelden sterben nicht. Zahlreiche Märchen fordern bis in die heutige Zeit zu humorvollen oder kritischen Auseinandersetzungen heraus. Ein Beispiel dafür ist Schneewittchen: welche Spannungen bestehen zwischen Prinzessin und Königin-Stiefmutter, zwischen dem jungen Mädchen und sieben Zwergen, wieso verliebt ein Prinz sich in eine Scheintote... Welche Wahrheit erzählen die Märchen?

Les contes ne sont jamais vraiment à la mode mais ils restent toujours modernes. Les héros des contes ne meurent pas. De nombreux contes inspirent des réflexions nouvelles - comme par exemple Blanche Neige: quels sont les conflits entre la princesse et sa belle-mère, entre la jeune fille et les sept nains? Pourquoi un prince tombe-t-il amoureux d'une morte en apparence ?... Quelle est la vérité que nous disent les contes? 